\title{
Testosterone insulin-like effects: an in vitro study on the short-term metabolic effects of testosterone in human skeletal muscle cells
}

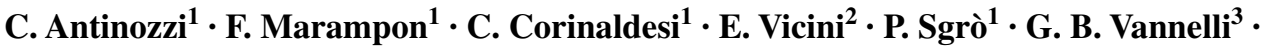 \\ A. Lenzi ${ }^{4}$ C. Crescioli ${ }^{1} \cdot$ L. Di Luigi ${ }^{1}$
}

Received: 26 January 2017 / Accepted: 4 May 2017 / Published online: 15 May 2017

(c) The Author(s) 2017. This article is an open access publication

\begin{abstract}
Purpose Testosterone by promoting different metabolic pathways contributes to short-term homeostasis of skeletal muscle, the largest insulin-sensitive tissue and the primary site for insulin-stimulated glucose utilization. Despite evidences indicate a close relationship between testosterone and glucose metabolism, the molecular mechanisms responsible for a possible testosterone-mediated insulinlike effects on skeletal muscle are still unknown.

Methods Here we used undifferentiated proliferating or differentiated human fetal skeletal muscle cells (Hfsmc) to investigate the short-term effects of testosterone on the insulin-mediated biomolecular metabolic machinery. GLUT4 cell expression, localization and the phosphorylation/activation of AKT, ERK, mTOR and GSK3 $\beta$ insulinrelated pathways at different time points after treatment with testosterone were analyzed.
\end{abstract}

Cristina Antinozzi, Francesco Marampon, Clara Crescioli and Luigi Di Luigi contributed equally to this work.

C. Crescioli

clara.crescioli@uniroma4.it

1 Department of Movement, Human and Health Sciences Section of Health Sciences, Unit of Endocrinology, Università degli Studi di Roma "Foro Italico", 00135 Rome, Italy

2 Department of Anatomical, Histological, Forensic and Orthopedic Sciences-Section of Histology and Medical Embryology, Sapienza University of Rome, Rome, Italy

3 Department of Experimental and Clinical Medicine, University of Florence, 50134 Florence, Italy

4 Department of Experimental Medicine, Sapienza University of Rome, Rome, Italy
Results Independently from cells differentiation status, testosterone, with an insulin-like effect, induced Glut4mRNA expression, GLUT4 protein translocation to the cytoplasmic membrane, while no effect was observed on GLUT4 protein expression levels. Furthermore, testosterone treatment modulated the insulin-dependent signal transduction pathways inducing a rapid and persistent activation of AKT, ERK and mTOR, and a transient inhibition of GSK3 $\beta$. T-related effects were shown to be androgen receptor dependent.

Conclusion All together our data indicate that testosterone through the activation of non-genomic pathways, participates in skeletal muscle glucose metabolism by inducing insulin-related effects.

Keywords Testosterone $\cdot$ Metabolism · Insulin · Human skeletal muscle cells

\section{Introduction}

Endogenous androgens [e.g., testosterone (T), dihydrotestosterone (DHT)] influence both reproductive and non-reproductive functions in humans through the regulation of early non-genomic and late-genomic biochemical pathways [1-3]. Whether androgens-mediated long-term effects have been largely characterized, few data exist on short-term effects. We know that acute physical exercise induces a rapid increase in the human serum endogenous levels of several circulating factors such as $\mathrm{T}$ [4-6], but the related short-term effects on T-targeted cells, such as skeletal muscle cells, have been not yet characterized. Skeletal muscle is the major tissue involved in glucose metabolism accounting for $\approx 85 \%$ of whole-body insulin-stimulated glucose uptake [7]. Data from animal models show that $\mathrm{T}$ 
influences glucose through non-genomic insulin-like mechanisms in adipocytes, cardiomyocytes and myoblast cells [8-11]. T insulin-like effects on human skeletal muscle cells has been not yet fully investigated. Considering the possible role of $\mathrm{T}$ in promoting skeletal muscle cells homeostasis and recovery, particularly during prolonged physical exercise and/or after ending exercise [12], we have hypothesized that the observed acute rapid $\mathrm{T}$ increases induced by physical activity could modulate insulin-related early nongenomic pathways, thus impacting on the glucose metabolism and promoting muscle cells metabolic homeostasis and/or recovery. We have investigated the short-term effects of $\mathrm{T}$ on human muscle metabolic functions in vitro using human cultures of fetal skeletal muscle cells (Hfsmc) [13] treated with $\mathrm{T}(100 \mathrm{nM})$ or insulin (I) $(100 \mathrm{nM})$. The gene expression of glucose transporter type 4, 3 and 1 (Glut4, Glut3 and Glut1, respectively), the translocation of GLUT4 and the activation of I-responsive protein kinase B (PKB/ AKT), extracellular-signal-regulated kinases (ERK1/2), mammalian target of rapamycin (mTOR), and glycogen synthase kinase $3 \beta$ (GSK3 $\beta$ ) were investigated.

\section{Materials and methods}

\section{Chemicals}

DMEM/Ham's F-12 medium (1:1) with and without phenol red, phosphate buffered saline (PBS) $\mathrm{Ca}^{2+} / \mathrm{Mg}^{2+}$ free, bovine serum albumin (BSA) fraction $\mathrm{V}$, glutamine, antibiotics, collagenase type IV, $\mathrm{NaOH}$, Bradford reagent, 4',6-Diamidino-2-phenylindole (DAPI) and all reagents for western blot were from Sigma-Aldrich (St. Louis, MO, USA). Fetal calf serum was from HyClone (Logan, UT). Testosterone (T6147) and bicalutamide (B9061) were purchased from Sigma-Aldrich (St. Louis, MO, USA). 2-Mercaptoethanol was purchased from Life Technologies, Inc. Laboratories (Grand Island, NY). Antibodies (Abs) for western blot and immunocytochemical analysis: rabbit polyclonal primary anti-phospho Ser2448 mTOR (p-mTOR), mTOR, Ser-473 AKT (p-AKT), AKT, Thr-44, and Tyr-42 ERK (p-ERK1/2), ERK2, Ser21/9 GSK $3 \beta$, GSK $3 \beta$, mouse monoclonal primary anti- $\beta$ actin were from Santa Cruz (Santa Cruz, CA, USA); rabbit polyclonal primary anti-GLUT4. Cy3-labeled secondary antibody were from Jackson Laboratory (Maine, USA), peroxidase secondary Abs, all reagents for SDSPAGE were from Millipore (Billerica, MA, USA). For RNA extraction TRIzol RNA Isolation reagent was purchased by Ambion $^{\mathrm{TM}}$; for reverse transcription $10 \mathrm{mM}$ dNTP Mix, Random Primers, RNaseOUTTM Ribonuclease inhibitor and SuperScript ${ }^{\circledR}$ III Reverse were purchased from Invitrogen. SYBR ${ }^{\circledR}$ Green PCR Master
Mix for qPCR was purchased from Life Technologies ${ }^{\mathrm{TM}}$ (Applied Biosystems ${ }^{\circledR}$ ). Primers were from invitrogen. Primers for Glut1: Fw CAAGACTGGAGTCATCATCAATGC, Rev: AGGATGCTCTCCCCAAGC; for Glut3: Fw CTCCTTTTCCGTCGGACTCT; for Glut4: Fw CACCCTCACCACCCTCTG, Rev CTTTTCCTTCCAAGCCACTG; for $\beta$ actin: FW CTGAACCCCAAGGCCAAC, Rev AGCCTGGATAGCAACGTACA. Plasticware for cell cultures and disposable filtration units for growth media preparation were purchased from Corning (Milan, Italy).

\section{Cell cultures}

Hfsmc were obtained as previously described [13, 14]. Cells were isolated from 11 fetal skeletal male muscles (four upper and seven lower limbs) obtained after voluntary abortion (10-12 weeks of gestation to set up fetal tissue sample collection previously used [15]). Legal abortions were performed in authorized hospitals and written consent was given by the patients for their human fetal tissue to be stored and used for research. The use of human fetal tissue for research purposes was approved by the Committee for investigation in humans of the Azienda Ospedaliero-Universitaria Careggi, Florence, Italy (protocol no 6783-04). All fetal tissue samples have been handled in the same way and maintained in ice-cold PBS until processed for culture preparation as described elsewhere [13, 14]. Confluent cell cultures were split into a 1:2-1:4 ratio using EDTA-trypsin solution $(0.2-0.5 \%)$, and used from 5 th to 12 th passage $(5 p-12 p)$.

\section{RNA extraction, reverse transcription and real-time quantitative PCR}

For mRNA analysis $35 \times 10^{3}$ Hfsmc were seeded and maintained for $24 \mathrm{~h}$ or 5 days in serum-free medium to differentiate in myotubes. Cells before and after differentiation were stimulated with $\mathrm{T}(100 \mathrm{nM})$ and $\mathrm{I}(100 \mathrm{nM})$ for $24 \mathrm{~h}$ in serum-free medium containing $0.1 \%$ BSA. Cells in serum-free medium with $0.1 \%$ BSA and vehicle were used as control. Total RNA and reverse-transcribedRNA were prepared as described elsewhere [16]. Singlestranded cDNA was obtained by reverse transcription of $1 \mu \mathrm{g}$ of total RNA. RT-qPCR was performed using 7500 Real Time System (Applied Biosystems ${ }^{\circledR}$ ) with SYBRgreen fluorophore; $40 \mathrm{ng}$ of cDNA were used as template and cycling parameters were $95{ }^{\circ} \mathrm{C}$ for $10 \mathrm{~min}$, followed by 40 cycles of $15 \mathrm{~s}$ at $95{ }^{\circ} \mathrm{C}, 1 \mathrm{~min}$ at $60{ }^{\circ} \mathrm{C}, 30 \mathrm{~s}$ at $95{ }^{\circ} \mathrm{C}, 15 \mathrm{~s}$ at $60^{\circ} \mathrm{C}$. Fluorescence intensities were analyzed using the manufacturer's software (7500 Software v2.05) and relative amounts were obtained using the 
$2^{-\Delta \Delta \mathrm{Ct}}$ method and normalized for the $\beta$-actin. Data are expressed as fold increase vs. control taken as 1 .

\section{Protein expression analysis}

For protein analysis, Hfsmc, seeded and maintained in the same conditions as previously reported [17], were stimulated for 15 and $30 \mathrm{~min}, 2,6$ and $12 \mathrm{~h}$ in presence or absence of $\mathrm{T}(100 \mathrm{nM})$ in serum-free medium containing $0.1 \%$ BSA; cells were treated for $15 \mathrm{~min}$ with $\mathrm{I}(100 \mathrm{nM})$ for comparison. Androgen receptor antagonism was obtained by pre-treating $\mathrm{Hfsmc}$ with $100 \mathrm{nM}$ of bicalutamide for $1 \mathrm{~h}$ before $\mathrm{T}$ treatments. Cells in serum-free medium with $0.1 \%$ BSA and vehicle were used as control. Protein concentration measurement was performed with Bradford Reagent. Protein aliquots $(20 \mu \mathrm{g})$ were processed, loaded onto $10 \%$ SDS-PAGE and transferred on PVDF membranes, according to the procedure previously described $[18,19]$. Thereafter, membranes were incubated with primary Abs appropriately diluted in Tween Tris-buffered saline (TTBS) (for anti-p-AKT, anti-AKT, anti-p-mTOR, anti-mTOR, anti-pERK1/2, anti ERK2, anti-p-GSK3 $\beta$, anti-GSK3 $\beta$ 1:1000; for anti- $\beta$ actin 1:5000), followed by peroxidase-conjugated secondary $\operatorname{IgG}(1: 10,000)$. Proteins were revealed by the enhanced chemiluminescence system (ECL plus; Millipore). Image acquisition was performed with Image Quant Las 4000 software (GE Healthcare) and densitometric analysis with Quantity One ${ }^{\circledR}$ software (Bio-Rad laboratories Inc.). Western blot analysis was performed in three/four independent experiments with different cell preparations.

\section{Immunofluorescence microscopy}

$10^{4}$ cells were seeded onto glass coverslips in growth medium and maintained for $24 \mathrm{~h}$ or 5 days in serum-free medium for differentiation. For GLUT4 localization cells were stimulated for $30 \mathrm{~min}$ with T $100 \mathrm{nM}$ and I $100 \mathrm{nM}$ in serum-free medium containing $0.1 \%$ BSA. Androgen receptor antagonism was obtained by pre-treating $\mathrm{Hfsmc}$ with $100 \mathrm{nM}$ of bicalutamide for $1 \mathrm{~h}$ before $\mathrm{T}$ treatments. Cells in serum-free medium with $0.1 \%$ BSA and vehicle were used as controls. For method specificity, slides lacking the primary Abs were processed. To evaluate GLUT4 translocation cells were fixed with 4\% PFA to leave intact plasmalemma and incubated with blocking buffer containing $1 \%$ BSA for $30 \mathrm{~min}$ at room temperature. Ab GLUT4 (1:100) was incubated overnight, followed by $\mathrm{Cy} 3$ conjugated secondary Ab (1.400). DAPI nucleic acid stain was used to dye nuclei $(1: 10,000)$. Images were acquired at $60 \times$ magnification and slides were examined with Zeiss Z1 microscope and Leica TCS SP2 (Leica, Milano, Italy). For quantification: the percentage of GLUT4 positive cells was calculated by counting the number of stained cells over the total in at least 10 separate fields per slide. Experiments were performed three times with different cell preparations.

\section{Statistical analysis}

The statistical analysis was performed using GraphPad Prism 5 software (GraphPad Software, Inc., La Jolla, CA, USA). $T$ test was applied and $P$ value $<0.05$ was considered significant and corrected for comparison using Bonferroni's post hoc test. Data were expressed as the mean \pm standard error (SEM).

\section{Results}

\section{Testosterone-induced Glut4 mRNA expression in undifferentiated and differentiated Hfsmc}

mRNA specific for glucose transporter subtypes Glut4, Glut 3 and Glut 1 was analyzed by qPCR analysis in undifferentiated or differentiated Hfsmc cells, treated for $24 \mathrm{~h}$ with $\mathrm{T}$ or $\mathrm{I}$, as shown in Fig. 1 . T significantly $(P<0.01)$ increased Glut 4 mRNA expression in undifferentiated (3.21 \pm 0.78 fold of induction vs. c) or differentiated (4.58 \pm 0.82 fold of induction vs. c) Hfsmc cells vs. basal expression (control) taken as 1 ; no changes were observed after I or T in Glut 1 and Glut 3 mRNA expression vs. control cells. Furthermore, $\mathrm{T}$ seems to retain a stronger efficiency in inducing mRNA Glut4 expression vs. I treatment $(2.12 \pm 0.11$-fold of induction vs. control) in Hfsmc differentiated cells.

\section{Testosterone-induced GLUT4 membrane recruitment in undifferentiated and differentiated Hfsmc}

The effect of T on GLUT4 localization was investigated. Immunofluorescence for GLUT4 performed onto nonpermeabilized undifferentiated $\mathrm{Hfsmc}$ treated with $\mathrm{T}$ for $30 \mathrm{~min}$ revealed a stronger positive signal vs. control cells, similarly to I, used as positive control (Fig. 2a, upper panels, undifferentiated).

Similar results were observed in non-permeabilized differentiated Hfsmc (differentiated), where positive specific staining for GLUT4 was stronger after T or I vs. control (Fig. 2a, upper panels, differentiated). Middle and lower panels of Fig. 2a depict, respectively, nuclei DAPI labeling and GLUT4/DAPI fluorescence merging for each conditions.

Percentage analysis of GLUT4 positive cells shows that T-mediated GLUT4 translocation was induced by $99.3 \% \pm 3.1$ and $83.4 \pm 9.9 \%$ in undifferentiated and in differentiated cells, respectively; $P<0.01$ vs. control. I 


\section{UNDIFFERENTIATED}
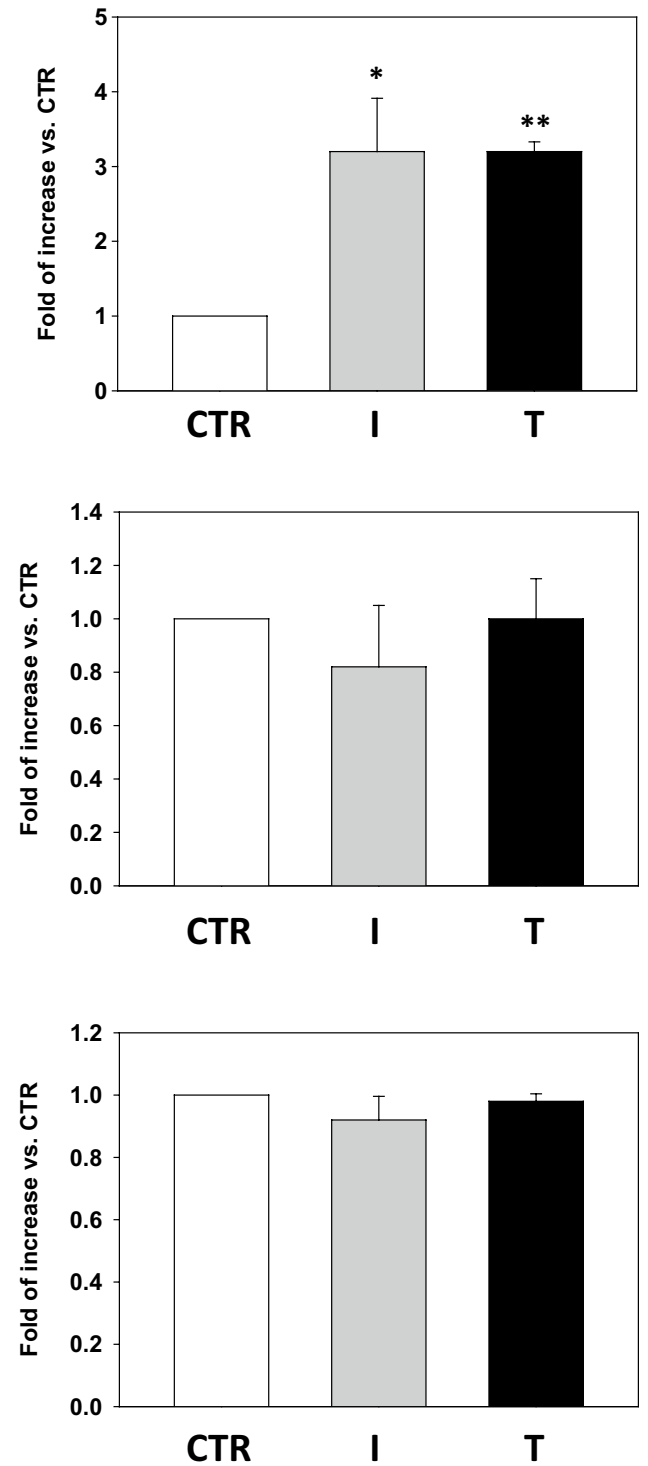

Fig. 1 Effect of testosterone on Glut4 mRNA expression. Glut1, Glut 3 and Glut 4 mRNA expression was evaluated in undifferentiated or differentiated Hfsmc treated for $24 \mathrm{~h}$ with $\mathrm{T}(100 \mathrm{nM})$ or I $(100 \mathrm{nM})$ for comparison. I or $\mathrm{T}$ treatment significantly increased

induced GLUT4 membrane recruitment in virtually $100 \%$ of undifferentiated and differentiated cells (Fig. 2b).

\section{Testosterone rapid effect on insulin-related pathway activation}

The effects of $\mathrm{T}$ onto I-related signal transduction pathways were investigated in undifferentiated Hfsmc cells treated with $\mathrm{T}$ for $15 \mathrm{~min}, 30 \mathrm{~min}, 2,6$ and $12 \mathrm{~h}$ vs. T0

\section{DIFFERENTIATED}
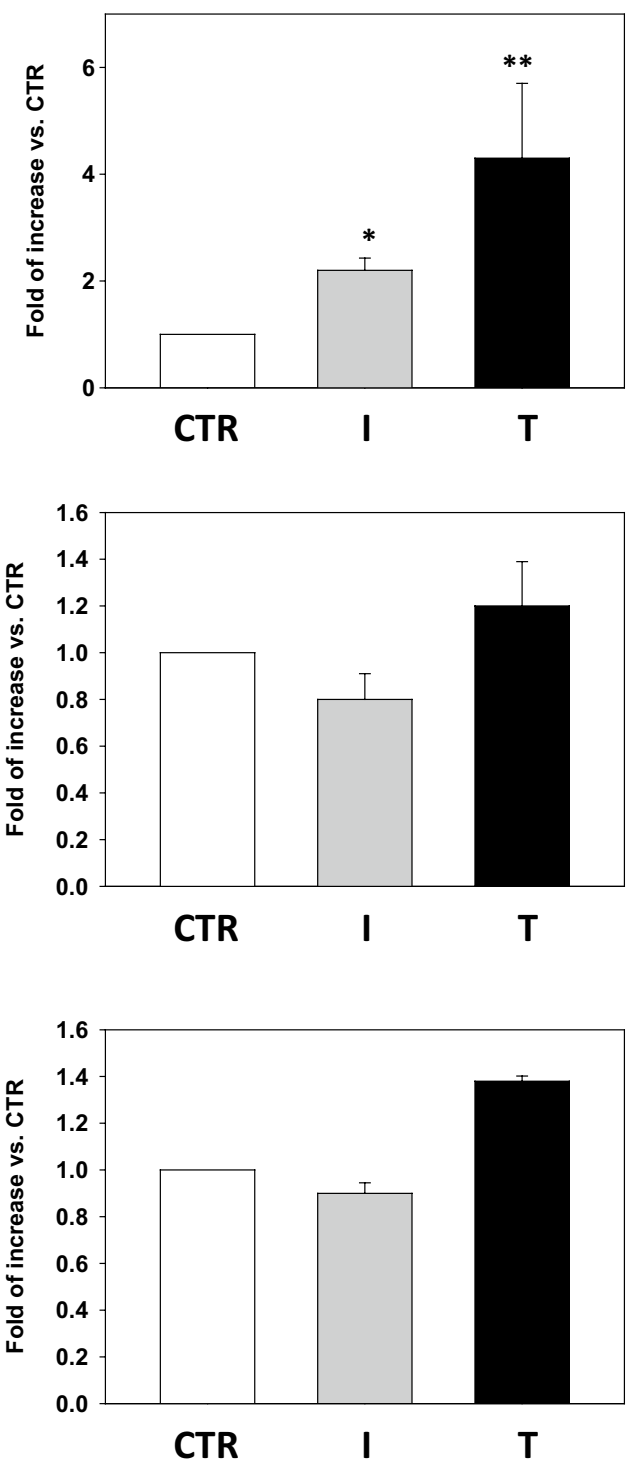

Glut4 mRNA vs. control (c) $\left({ }^{*} P<0.05\right.$; $\left.* * P<0.01\right)$; no difference was observed in Glut subtype 1 and 3 mRNA expression. Results (mean $\pm \mathrm{SE}$ ) are derived from three experiments with different cell preparations and expressed as fold increase vs. ctr, taken as 1

(time before stimuli addition); 15 min I treatment was used as positive control. $\mathrm{T}$ significantly induced a rapid and persistent ( $30 \mathrm{~min}$ to $12 \mathrm{~h}$ ) phosphorylation/activation of AKT, ERK1/2 and mTOR signaling transduction pathways $(P<0.05$ or $P<0.01$ vs. T0) while a transient $(30 \mathrm{~min})$ phosphorylation/inactivation of GSK3 $\beta$ $(P<0.05$ vs. T0) (Fig. 3a-d). No effects were described on GLUT4 protein expression levels (Fig. 3e). 


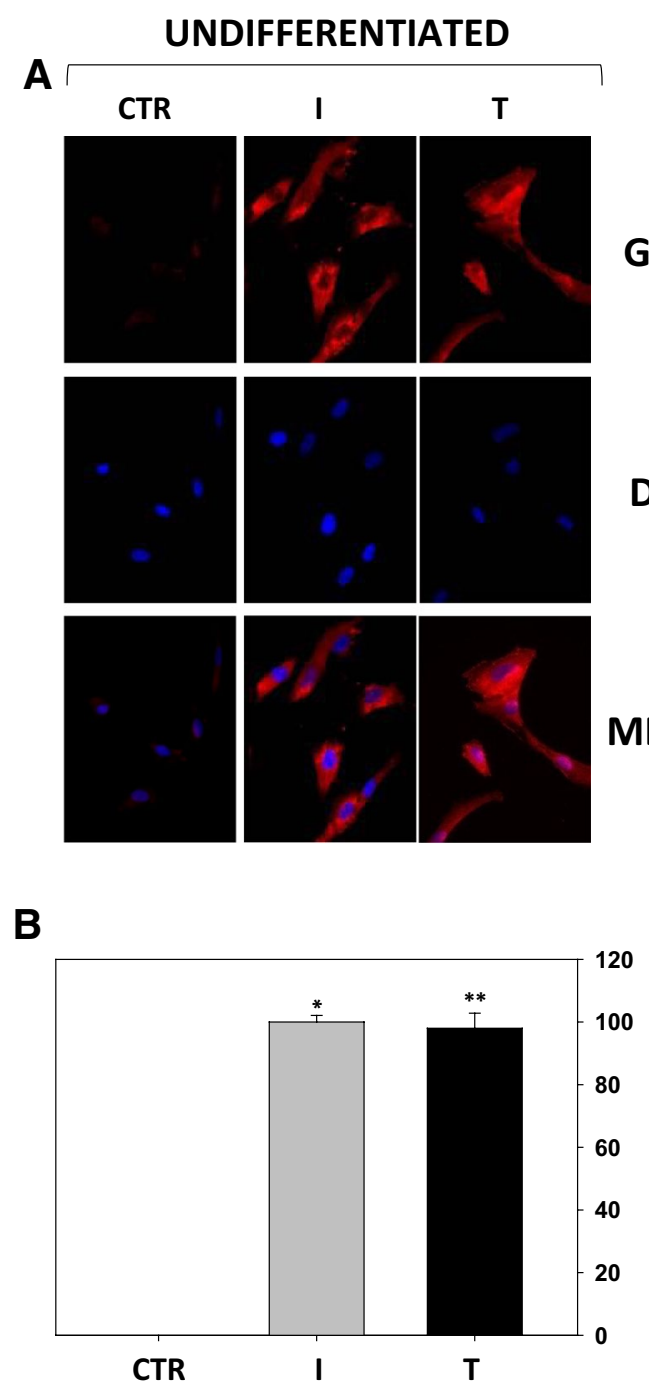

Fig. 2 Effect of testosterone on GLUT4 translocation in Hfsmc, before and after differentiation. Immunofluorescence analysis (a) revealed no signal for GLUT4 membrane expression in control (ctr) untreated undifferentiated or differentiated Hfsmc; positive staining for GLUT4 was observed after 30-min incubation with I (100 nM) or $\mathrm{T}(100 \mathrm{nM})$ both in undifferentiated or differentiated conditions (upper panels). Cells were incubated with antibody probes specific

\section{Bicalutamide counteracts testosterone effects on GLUT4 trafficking and insulin-related pathway activation}

The role of AR on T-related GLUT4 trafficking and signaling was investigated in $1 \mathrm{~h}$ pre-treated $\mathrm{Hfsmc}$ cells with the AR antagonist bicalutamide (Bic, $100 \mathrm{nM}$ ) then treated with $\mathrm{T}(100 \mathrm{nM})$ for $30 ; 15 \mathrm{~min}$ I treatment was used as positive control.

Immunofluorescence for GLUT4 revealed that Bic pretreatment counteracted the GLUT4 signal immunodecoration induced by $\mathrm{T}$ (Fig. 4a, upper panels). Furthermore,
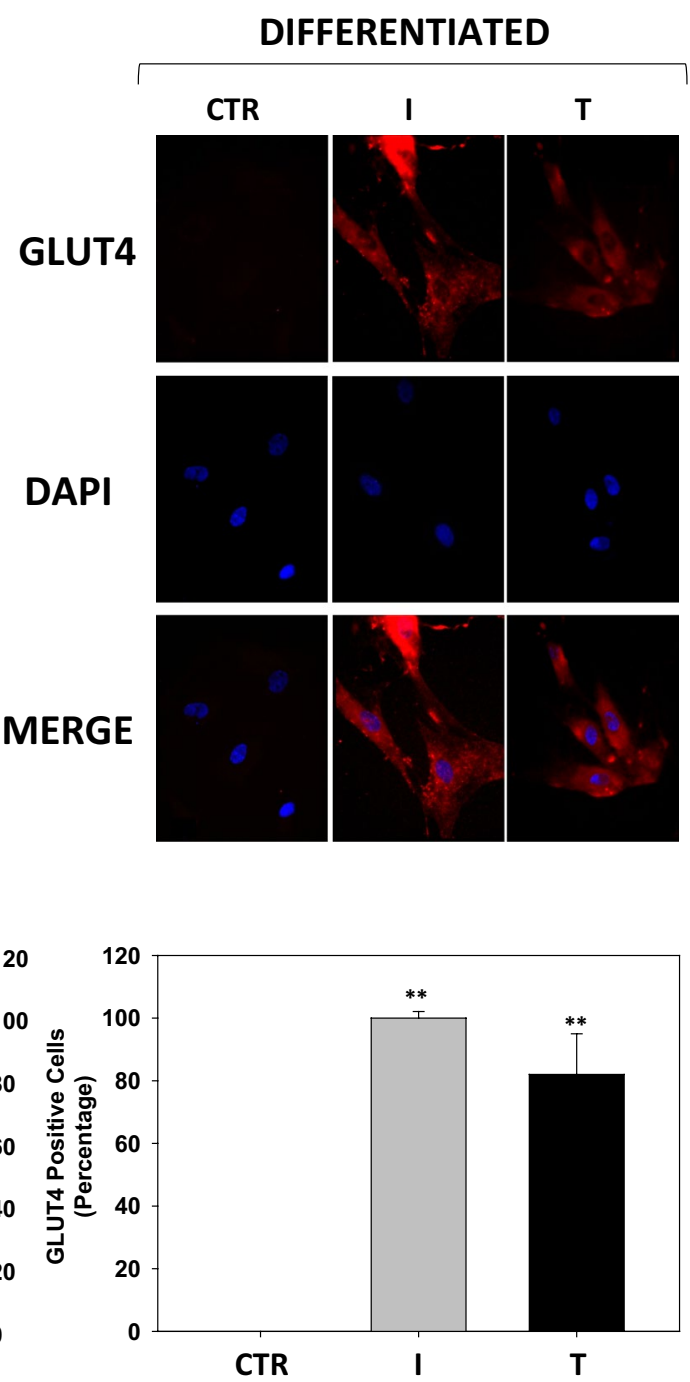

for GLUT4, followed by incubations with fluorescent secondary antibody. Middle panels represent DAPI blue staining of nuclei; lower panels depict GLUT4/DAPI staining merge. Pictures are representative. Results are derived from four separate experiments, using distinct cell preparations. Percentage of GLUT4 positive undifferentiated or differentiated cells $(* * P<0.01 \mathrm{vs}$. ctr) are represented in panels of figure $\mathbf{b}$, respectively. Data are expressed as mean $\pm \mathrm{SE}$

AR antagonism by Bic reduced GLUT4 signal basal levels (Fig. 4a, upper panels). Middle and lower panels (Fig. 4a) depict, respectively, nuclei DAPI labeling and GLUT4/DAPI fluorescence merging for each condition. Percentage analysis of GLUT4 positive cells shows that Bic pre-treatment significantly counteracted T-mediated GLUT4 translocation by $81.82 \% \pm 2.4$ (Fig. 4b, $P<0.001 \mathrm{Bic}+\mathrm{T}$ vs. T).

Western blot (Fig. 5) showed that Bic pre-treatment significantly counteracted T-related phosphorylation/activation of AKT, ERK1/2, mTOR and GSK3 $\beta$ signaling transduction pathways $(P<0.05$ or $P<0.001$ vs. T) (Fig. $5 \mathrm{a}-\mathrm{d})$. 

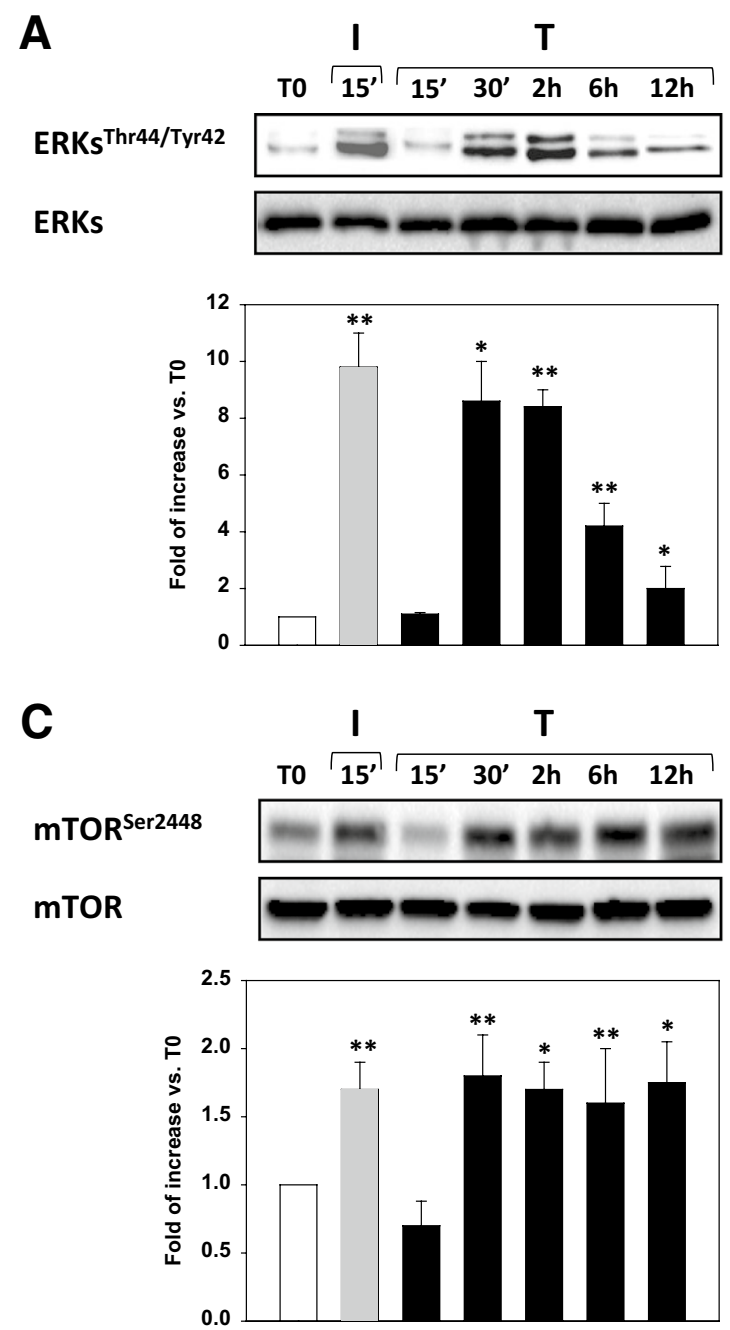

$\mathbf{E}$
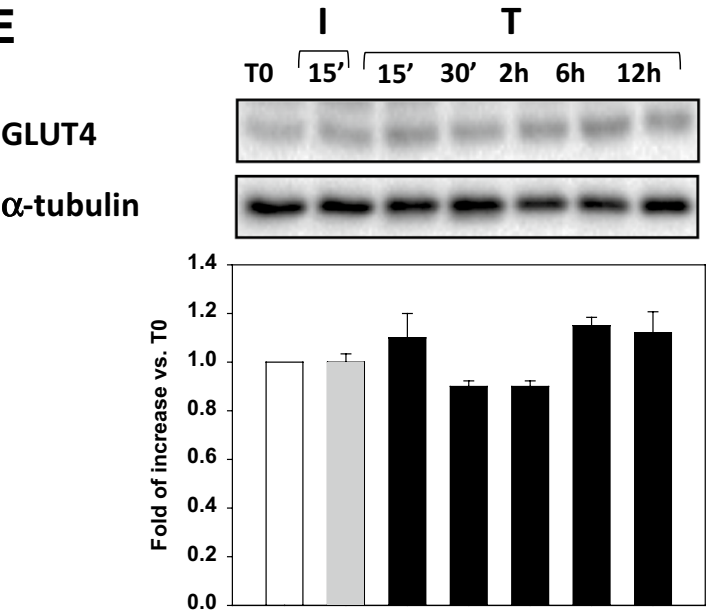

Fig. 3 Effect of testosterone on I-related metabolic pathways. The treatment of $\mathrm{Hfsmc}$ for $15 \mathrm{~min}$ with $\mathrm{T}(100 \mathrm{nM})$ did not activate any of the tested intracellular paths, at variance with $\mathrm{I}(100 \mathrm{nM})$, used as positive control, (a-d); however, $\mathrm{T}$ after $30 \mathrm{~min}$ significantly induced activation of phospho (p)-AKT, ERK1/2, mTOR and GSK3 $\beta$ $(* P<0.05$ or $* * P<0.01$ vs. T0), as depicted by the densitometric
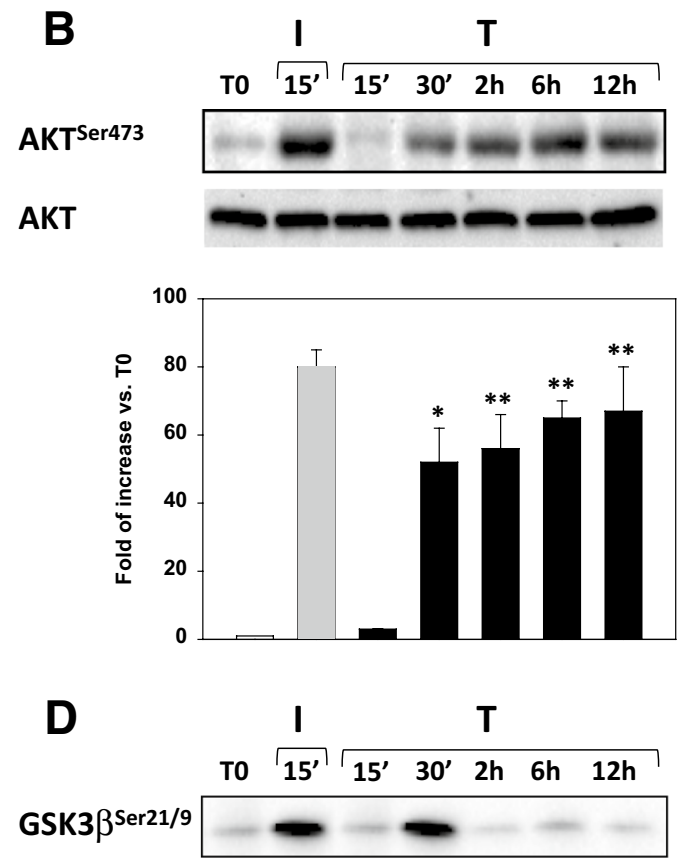

GSK3 $\beta$
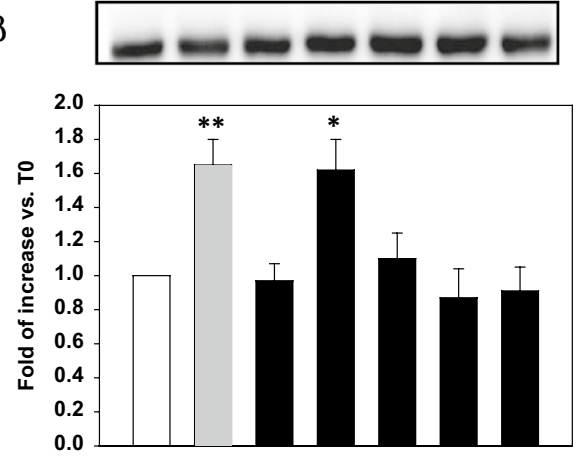

analysis, reported below each representative blot. Specific total proteins were used as loading controls. Results of densitometric analysis (mean $\pm \mathrm{SE}$ ) are expressed as ratio $\mathrm{p}$-/total-protein, fold increase vs. T0, taken as 1; data derived from three/four experiments using different cell preparations. Protein analysis revealed no time-dependent changes of GLUT4 expression (e) 
A

CTR
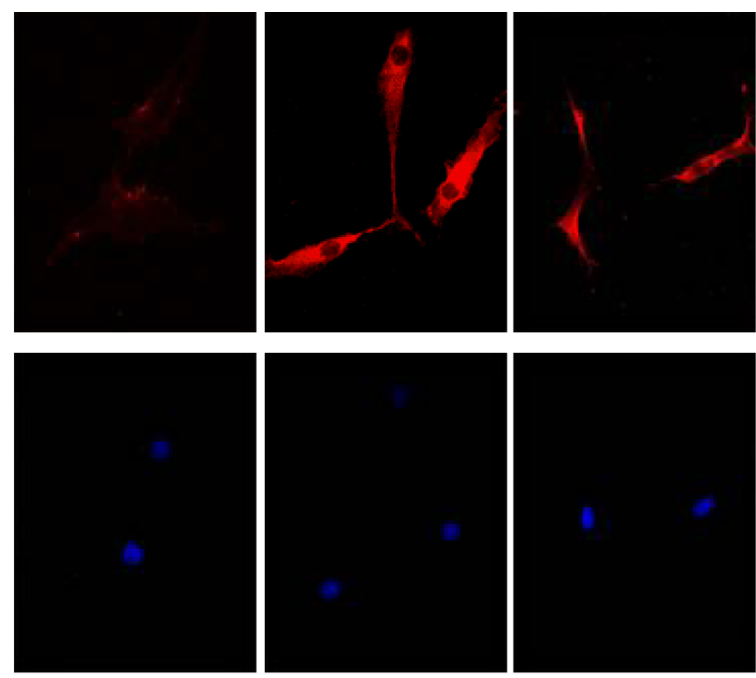

DAPI
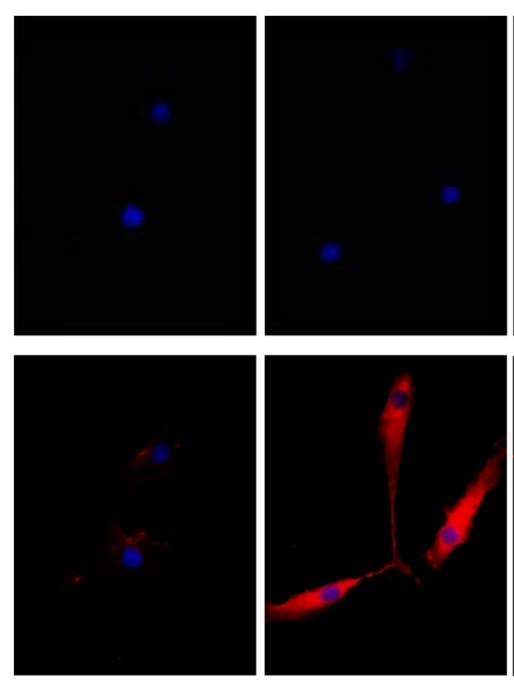

Bic+T
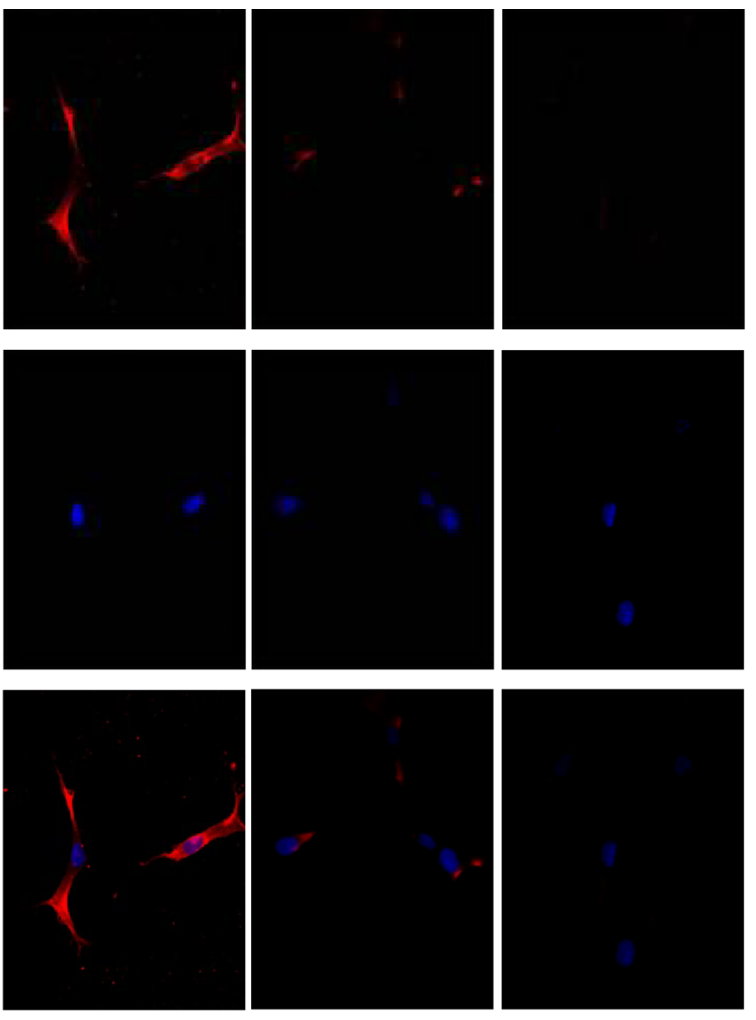

B

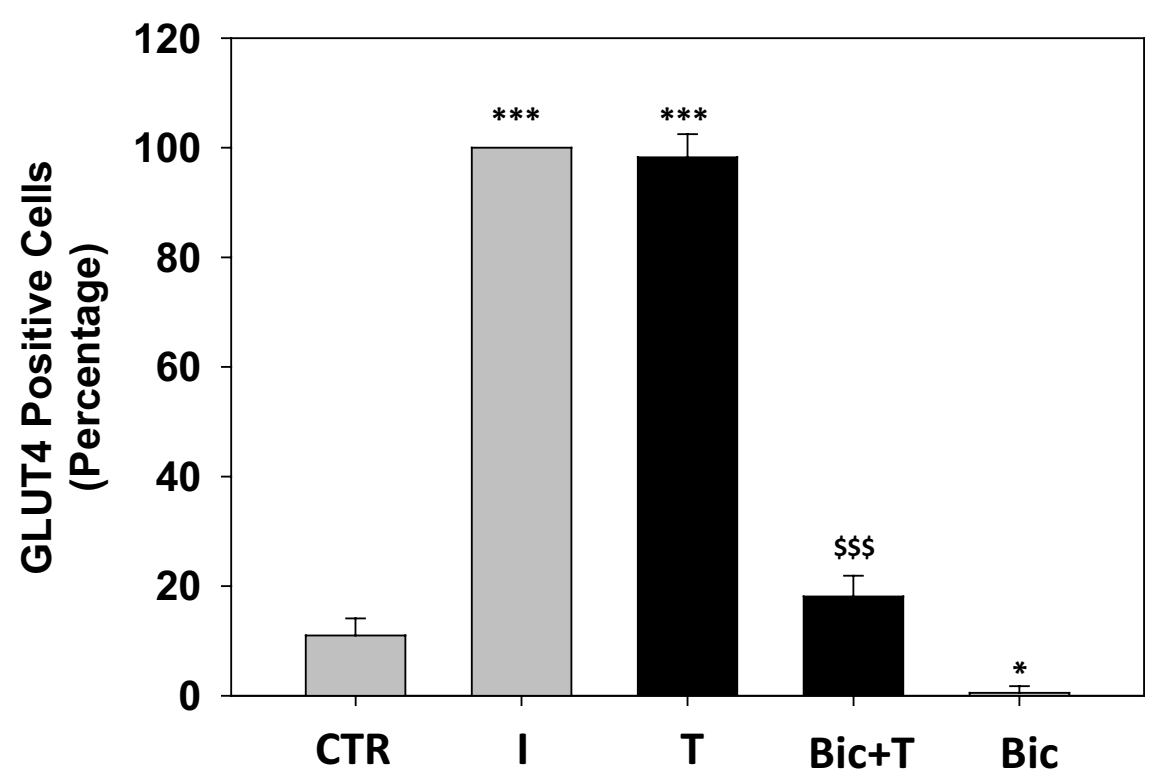

Fig. 4 Effect of bicalutamide pre-treatment on testosterone-induced GLUT4 translocation in Hfsmc. Immunofluorescence analysis (a) revealed no signal for GLUT4 membrane expression in control (ctr) untreated Hfsmc; positive staining for GLUT4 was observed after 30 -min incubation with I $(100 \mathrm{nM})$ or T $(100 \mathrm{nM})$ (upper panels). 1-h pre-treatment with Bic $100 \mathrm{nM}$ completely counteracted T-induced GLUT4 translocation. Cells were incubated with antibody probes specific for GLUT4, followed by incubations with fluorescent secondary antibody. Middle panels represent DAPI blue staining of nuclei; lower panels depict GLUT4/DAPI staining merge. Pictures are representative. Results are derived from four separate experiments, using distinct cell preparations. Percentage of GLUT4 positive cells $\left(* P<0.05\right.$, $* * * P<0.001$ vs. ctr and ${ }^{\$ \$} P<0.001$ vs. T) are represented in $\mathbf{b}$. Data are expressed as mean $\pm \mathrm{SE}$ 

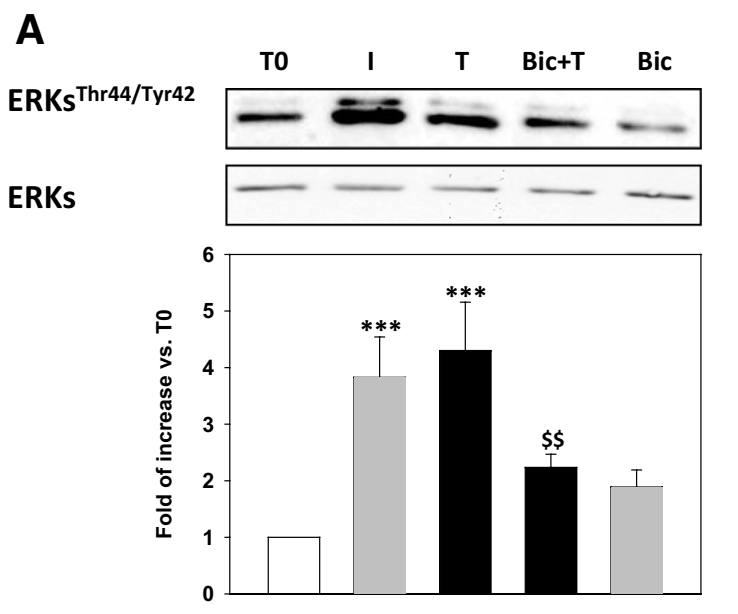

C
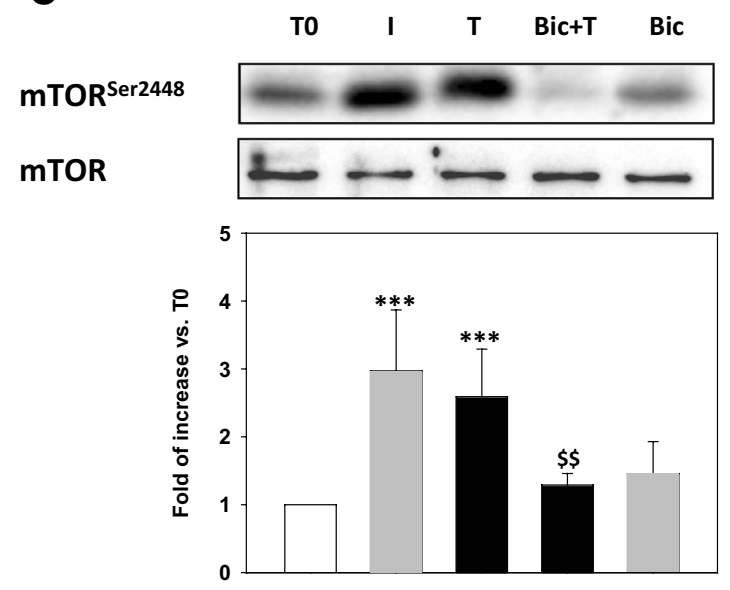

Fig. 5 Effect of bicalutamide on Testosterone-induced I-related metabolic pathways. The pre-treatment with bicalutamide $(100 \mathrm{nM}$, Bic) prevented T-induced phosphorylation (p) of AKT, ERK1/2, mTOR and GSK3 $\beta(* P<0.05, * * P<0.01$ or $* * * P<0.001$ vs. T0), as depicted by the densitometric analysis, reported below each repre-

\section{Discussion}

Herein for the first time we showed that $\mathrm{T}$ exerts an I-like effect in human skeletal muscle cells, promoting GLUT4 translocation and activating I-dependent signal transduction pathway.

Skeletal muscle system, essential for the postural retention and locomotion has been shown to be an active organ able to dynamically respond to several molecules involved in the regulation of body metabolism, physiologic or pathologic processes, such as $\mathrm{T}$ and $\mathrm{I}$, among other factors [5-7, 20, 21]. I, targeting muscle, govern carbohydrate, lipid and protein metabolism [22], while $\mathrm{T}$ seemed to mainly affect the body composition [23]. Despite $\mathrm{T}$ and $\mathrm{I}$ have distinct functions, several evidences
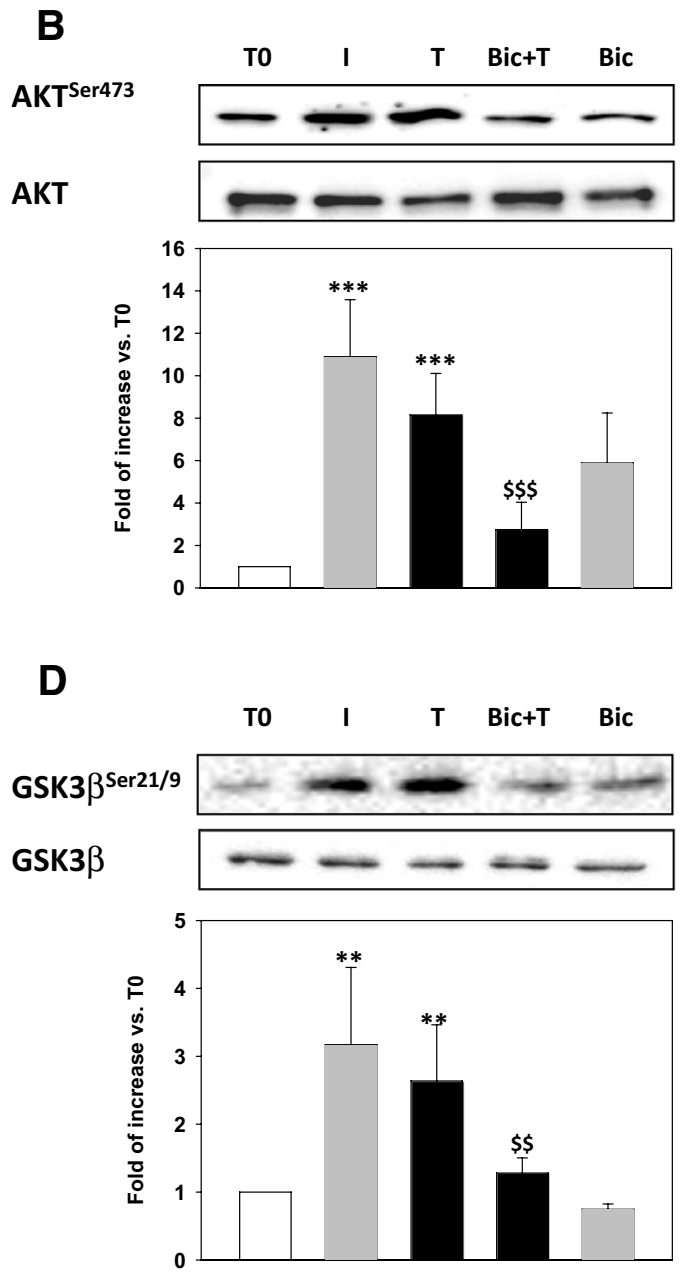

sentative blot. Specific total proteins were used as loading controls. Results of densitometric analysis (mean $\pm \mathrm{SE}$ ) are expressed as ratio p-/total-protein, fold increase vs. T0, taken as 1; data derived from three/four experiments using different cell preparations

suggest their potential interplay both in physiological and in pathological conditions. T-increased levels by physical activity have been shown to play a key role in skeletal muscle tissue homeostasis, metabolism and recovery from exercise-induced stress [9-11, 23]. T lower levels in men affected by hypogonadism and higher in women with polycystic ovary syndrome have been related with an increased risk of metabolic syndrome and diabetes [24-27]. Inversely, type 2 diabetes is frequently associated to reduced $\mathrm{T}$ levels [28]. In line with our in vitro results, $\mathrm{T}$ has been shown in humans to exert beneficial effects on non-alcoholic fatty liver disease-related insulin resistance, indicating a direct insulin-like effect of testosterone in skeletal muscle cells [29].

Thus, T, for many years considered the "male hormone" with a "muscular hypertrophying function" seems 
to influence glucose metabolism independently by gender. Starting from these evidences, we documented for the first time in human skeletal muscle cells that $\mathrm{T}$, similarly to I, shortly activates the intracellular machinery committed to metabolic glucose control.

GLUT4 mediates glucose uptake in adipose tissues and striated muscle. After binding to receptor, I induces the rapid (minutes) translocation of GLUT4 to the cell surface that promotes glucose uptake [30] and induces later (hours) effects on Glut4 mRNA expression [31, 32]. Recently, it has been shown that high-dose testosterone promotes GLUT4 translocation and dependent glucose uptake in 3T3-L1 adipocytes cells [9] while no data have been yet collected on human muscle cells. Herein, our results show that in non-permeabilized human skeletal muscle cells, independently from the differentiation status, $30 \mathrm{~min}$ of $\mathrm{T}$ treatment induced an intense signal specific for GLUT4 protein, virtually absent in control non-treated cells, when GLUT4 is reported to be masked within storage compartments [33], comparable to which described after I treatment. Furthermore, we show that $24 \mathrm{~h}$ of $\mathrm{T}$ treatment upregulate Glut 4 mRNA expression without affecting Glut 1 and Glut 3 mRNA levels. To date, 14 glucose transporters isoforms with a specific pattern of tissue expression have been identified [34]. Whether GLUT4 has been found specifically expressed in adipose tissues and striated muscle (skeletal muscle and cardiac muscle), GLUT1 and GLUT3 result, respectively, expressed in erythrocytes [35] or endothelial cells of barrier tissues [36] and in neurons or in the placenta [37]. Our results document the ability of $T$ to regulate, as I, the expression and trafficking of GLUT4 isoform implied in skeletal muscle glucose metabolism.

Following binding to receptor, I activates several signal transduction pathways essential for the GLUT4 recruitment and the regulation of several cell functions, pertinent to metabolic or proliferative effects [38]. Principally, I activates the p21ras/MAP kinase (MAPK) (RAS)/extracellular-signal-regulated kinase (ERK) and the Phosphoinositide 3-kinase (PI3 K)/AKT pathways known to play different role in I-mediated effects. Particularly, whether MAPK/ ERK signaling controls cellular proliferation or differentiation, PI3K/AKT influences GLUT4 trafficking and glucose uptake through the phosphorylation-activation of mTOR and -inhibition of GSK3 $\beta$ [39-42]. By time-course experiments, we showed that $\mathrm{T}$ induced an early and persistent phosphorylation/activation of PI3K/AKT/mTOR and RAS/ ERK paths that starts from $30 \mathrm{~min}, 15 \mathrm{~min}$ later than I, and lasted up to $12 \mathrm{~h}$ as well as a transient phosphorylation/ inhibition of GSK3 $\beta$. Notably, PI3K/AKT signaling is also involved in the regulation of GLUT4 protein expression by increased biosynthesis, decreased degradation or both [41]. Herein, $\mathrm{T}$ or I treatment increased Glut4 mRNA, but not protein expression. Whether many studies correlate I levels, skeletal muscle cells responsiveness and Glut 4 mRNA levels [42], no evidences have still been collected on protein expression status. Recently Ma et al. showed that the prolonged I stimulation down-regulates GLUT4 in 3T3-L1 adipocytes [43]. Analyzing our data we can suppose that $T$ as I increases the GLUT4 protein turnover that is rapidly counteracted by an increase in Glut4 gene transcription and translation. Thus, we speculate that whether it is possible to check up-regulation in mRNA expression no modifications can be described on protein expression levels. The molecular mechanisms by which I and T acutely and chronically regulate GLUT4 half-life will be object of future investigations. All together, the effects herein shown indicate that $\mathrm{T}$ is able to induce rapid I-like effects in muscles.

The classical mechanism of $\mathrm{T}$ action provides that $\mathrm{T}$ binding the androgen receptors (AR) activates AR increasing its affinity for specific DNA-binding sites thus promoting, through the recruitment of co-activators or co-repressors, gene expression regulation. In addition to the classical mechanism, previous studies have determined that androgens can activate cellular signaling pathways independent of AR binding to DNA [1-3]. This "non-classical" mechanism has been shown to increase the phosphorylation/ activation of the PI3K/AKT and RAS/ERK pathways in mouse skeletal and rat cardiac muscle fibers [1-3, 43, 44]. Analyzing our data, we can speculate that in human skeletal muscle cells $\mathrm{T}$ affects glucose metabolism through the AR-mediated activation of the classic pathway, responsible for Glut 4 mRNA expression, and the non-classic pathway that activate $\mathrm{PI} 3 \mathrm{~K} / \mathrm{AKT}$ rapidly predispose cells to glucose uptake. Whether mRNA up-regulation mirrors this rapid effect, belongs to the classic pathway or involves both the ways, has to be elucidated.

In conclusion, our in vitro data provide some biomolecular evidences for I-like effects of $\mathrm{T}$ in human skeletal muscle cells, thus sustaining also the role of this hormone in exerting a short-term direct metabolic control on muscle. Considering the observed rapid physiological increases of $\mathrm{T}$ during acute physical exercise, the possible presence of both static and dynamic roles of $\mathrm{T}$ in supporting metabolic muscle homeostasis and function in resting conditions, during exercise and recovery should be considered. In this sense, we can speculate that in in vivo the $\mathrm{T}$ increases rapidly during physical exercise, also throughout its I-like rapid and prolonged effects, that are essential to control skeletal muscle cell function and metabolic homeostasis, particularly during prolonged exercise and/or during recovery. Consequently, further studies are necessary to investigate if these different I-like effects of $\mathrm{T}$ are also confirmed in vivo and to verify if during/after exercise they are related to the reached maximum $\mathrm{T}$ concentration per se (i.e., does it exist a critical $\mathrm{T}$ concentration?) and/or to the observed 
rapid serum $\mathrm{T}$ concentration variation. Besides both the individual responsiveness to $\mathrm{T}$ and the role of genetic factors in the physiologic hormones adaptation to exercise-related stress [45], the possible relationships in vivo between $\mathrm{T}$ rapid increases and I-like metabolic pathways should be evaluated also in healthy athletes assuming supplements [46] and/or abusing with prohibited [47, 48] and not prohibited [49-52] drugs influencing endocrinemetabolic pathways. Moreover, if our data are confirmed we could also state that athletes often acutely abuse with $\mathrm{T}$ also because of the rapid effects on $\mathrm{T}$ metabolic I-related pathways, in addition to possible rapid effects of $\mathrm{T}$ on neuromuscular system [53]. In fact, from anecdotal reports, athletes could have a benefit for performance by abusing with a single dose of $\mathrm{T}$ immediately before or during a competition [54].

\section{Compliance with ethical standards}

Conflict of interest The authors have nothing to declare and no conflict of interest. All authors have read and approved the final manuscript.

Ethical approval This article does not contain any studies with human participants or animals performed by any of the authors.

Informed consent For this type of study formal consent is not required.

Funding This work was funded by grants from the Italian Ministry of Instruction, University and Research (PRIN 2010C8ERKX_002).

Open Access This article is distributed under the terms of the Creative Commons Attribution 4.0 International License (http://creativecommons.org/licenses/by/4.0/), which permits unrestricted use, distribution, and reproduction in any medium, provided you give appropriate credit to the original author(s) and the source, provide a link to the Creative Commons license, and indicate if changes were made.

\section{References}

1. Foradori CD et al (2008) Non-genomic actions of androgens. Front Neuroendocrinol 29(2):169-181

2. Rahman F et al (2007) Non-classical actions of testosterone: an update. Trends Endocrinol Metab 18(10):371-378

3. Michels G et al (2008) Rapid actions of androgens. Front Neuroendocrinol 29(2):182-198

4. Sgrò $P$ et al (2014) Testosterone responses to standardized shortterm sub-maximal and maximal endurance exercises: issues on the dynamic adaptive role of the hypothalamic-pituitary-testicular axis. J Endocrinol Investig 37(1):13-24

5. Brunelli A et al (2012) Acute exercise modulates BDNF and proBDNF protein content in immune cells. Med Sci Sports Exerc 44(10): 1871-1880
6. Peake JM et al (2015) Cytokine expression and secretion by skeletal muscle cells: regulatory mechanisms and exercise effects. Exerc Immunol Rev 21:8-25

7. Argilés JM et al (2016) Skeletal muscle regulates metabolism via interorgan crosstalk: roles in health and disease. J Am Med Dir Assoc 17(9):789-796

8. Kowalski GM et al (2014) The regulation of glucose metabolism: implications and considerations for the assessment of glucose homeostasis in rodents. Am J Physiol Endocrinol Metab 307(10):E859-E871

9. Mitsuhashi K et al (2016) Testosterone stimulates glucose uptake and GLUT4 translocation through LKB1/AMPK signaling in 3T3-L1 adipocytes. Endocrine 51(1):174-184

10. Wilson C et al (2013) Testosterone increases GLUT4dependent glucose uptake in cardiomyocytes. J Cell Physiol 228(12):2399-2407

11. Sato K et al (2008) Testosterone and DHEA activate the glucose metabolism-related signaling pathway in skeletal muscle. Am J Physiol Endocrinol Metab 294(5):E961-E968

12. Ahtiainen JP et al (2011) Recovery after heavy resistance exercise and skeletal muscle androgen receptor and insulin-like growth factor-I isoform expression in strength trained men. J Strength Cond Res 25(3):767-777

13. Crescioli $\mathrm{C}$ et al (2012) Inflammatory response in human skeletal muscle cells: CXCL10 as a potential therapeutic target. Eur J Cell Biol 91:139-149

14. Antinozzi C et al (2017) Potential role for the VDR agonist elocalcitol in metabolic control: evidences in human skeletal muscle cells. J Steroid Biochem Mol Biol 167:169-181. doi:10.1016/j. jsbmb.2016.12.010

15. Gallina $\mathrm{P}$ et al (2008) Development of human striatal anlagen after transplantation in a patient with Huntington's disease. Exp Neurol 213(1):241-244

16. Vulcano F et al (2006) HDAC inhibition is associated to valproic acid induction of early megakaryocytic markers. Exp Cell Res 312(9):1590-1597

17. Crescioli $\mathrm{C}$ et al (2013) Insulin-like effect of the phosphodiesterase type 5 inhibitor tadalafil onto male human skeletal muscle cells. J Endocrinol Investig 36(11):1020-1026

18. Marchiani $S$ et al (2006) The vitamin D analogue BXL-628 inhibits growth factor-stimulated proliferation and invasion of DU145 prostate cancer cells. J Cancer Res Clin Oncol 132(6):408-416

19. Gravina GL et al (2013) PXD101 potentiates hormonal therapy and prevents the onset of castration-resistant phenotype modulating androgen receptor, HSP90, and CRM1 in preclinical models of prostate cancer. Endocr Relat Cancer 20(3):321-337

20. Karstoft $\mathrm{K}$ et al (2016) Skeletal muscle as a gene regulatory endocrine organ. Curr Opin Clin Nutr Metab Care 19(4):270-275

21. Scolletta S et al (2013) Vitamin D receptor agonist target CXCL10: new therapeutic tools for resolution of inflammation. Mediators Inflamm. doi:10.1155/2013/876319

22. Dimitriadis G et al (2011) Insulin effects in muscle and adipose tissue. Diabetes Res Clin Pract 93(Suppl 1):S52-S59

23. Herbst KL et al (2004) Testosterone action on skeletal muscle. Curr Opin Clin Nutr Metab Care 7(3):271-277

24. Blaya $\mathrm{R}$ et al (2016) Total testosterone levels are correlated to metabolic syndrome components. Aging Male 19(2):85-89

25. Rotter I et al (2015) Analysis of relationships between the concentrations of total testosterone and dehydroepiandrosterone sulfate and the occurrence of selected metabolic disorders in aging men. Aging Male 18(4):249-255

26. Legro RS et al (1999) Prevalence and predictors of risk for type 2 diabetes mellitus and impaired glucose tolerance in polycystic ovary syndrome: a prospective, controlled study in 254 affected women. J Clin Endocrinol Metab 84(1):165-169 
27. Isidori AM et al (2015) Outcomes of androgen replacement therapy in adult male hypogonadism: recommendations from the Italian society of endocrinology. J Endocrinol Investig 38(1):103-112

28. Dhindsa $S$ et al (2004) Frequent occurrence of hypogonadotropic hypogonadism in type 2 diabetes. J Clin Endocrinol Metab 89(11):5462-5468

29. Mody A et al (2015) Relevance of low testosterone to non-alcoholic fatty liver disease. Cardiovasc Endocrinol 4(3):83-89

30. Leto D et al (2012) Regulation of glucose transport by insulin: traffic control of GLUT4. Nat Rev Mol Cell Biol 13(6):383-396

31. Flores-Riveros JR et al (1993) Insulin down-regulates expression of the insulin-responsive glucose transporter (GLUT4) gene: effects on transcription and mRNA turnover. Proc Natl Acad Sci USA 90(2):512-516

32. Yu ZW et al (2001) Insulin can enhance GLUT4 gene expression in 3T3-F442A cells and this effect is mimicked by vanadate but counteracted by cAMP and high glucose-potential implications for insulin resistance. Biochim Biophys Acta. 1535(2):174-185

33. Thorens B et al (2010) Glucose transporters in the 21st Century. Am J Physiol Endocrinol Metab 298(2):E141-E145

34. Montel-Hagen A et al (2009) Erythroid glucose transporters. Curr Opin Hematol 16(3):165-172

35. Klepper J et al (2002) Facilitated glucose transporter protein type 1 (GLUT1) deficiency syndrome: impaired glucose transport into brain — a review. Eur J Pediatr 161(6):295-304

36. Illsley NP (2000) Glucose transporters in the human placenta. Placenta 21(1):14-22

37. Simpson IA et al (2008) The facilitative glucose transporter GLUT3: 20 years of distinction. Am J Physiol Endocrinol Metab 295(2):E242-E253

38. Boucher $\mathbf{J}$ et al (2014) Insulin receptor signaling in normal and insulin-resistant states. Cold Spring Harb Perspect Biol 6(1):a009191

39. Haruta $T$ et al (1995) Insulin-stimulated GLUT4 translocation is mediated by a divergent intracellular signaling pathway. J Biol Chem. 270(47):27991-27994

40. Nikoulina SE et al (2002) Inhibition of glycogen synthase kinase 3 improves insulin action and glucose metabolism in human skeletal muscle. Diabetes 51(7):2190-2198

41. Watson RT et al (2004) Regulated membrane trafficking of the insulin-responsive glucose transporter 4 in adipocytes. Endocr Rev 25(2):177-204
42. Ma J et al (2014) Prolonged insulin stimulation down-regulates GLUT4 through oxidative stress-mediated retromer inhibition by a protein kinase CK2-dependent mechanism in 3T3-L1 adipocytes. J Biol Chem. 289(1):133-142

43. Basualto-Alarcón $\mathrm{C}$ et al (2013) Testosterone signals through mTOR and androgen receptor to induce muscle hypertrophy. Med Sci Sports Exerc 45(9):1712-1720

44. Lee WJ (2009) Insulin-like growth factor-I-induced androgen receptor activation is mediated by the $\mathrm{PI} 3 \mathrm{~K} /$ Akt pathway in C2C12 skeletal muscle cells. Mol Cells 28(5):495-499

45. Di Luigi L et al (2003) Heredity and pituitary response to exercise-related stress in trained men. Int $\mathrm{J}$ Sports Med 24(8):551-558

46. Di Luigi L (2008) Supplements and endocrine system in athletes. Clin Sports Med 27(1):131-151

47. Di Luigi L et al (2005) Androgenic anabolic steroids abuse in males. J Endocrinol Investig 28(3):81-84

48. Baldari $\mathrm{C}$ et al (2009) Is explosive performance influenced by androgen concentrations in young male soccer players? Br J Sports Med 43(3):191-194

49. Di Luigi L et al (2008) The type 5 phosphodiesterase's inhibitor tadalafil influences salivary cortisol, testosterone and dehydroepiandrosterone sulfate response to maximal exercise in healthy man. J Clin Endocrinol Metab 93(9):3510-3514

50. Di Luigi L et al (2007) Do non-steroidal anti-inflammatory drugs influence the steroid hormone milieu in male athletes? Int J Sport Med 28(10):809-814

51. Sabatini S, Sgrò P, Duranti G, Ceci R, Di Luigi L (2011) Tadalafil alters energy metabolism in $\mathrm{C} 2 \mathrm{C} 12$ skeletal muscle cells. Acta Biochim Pol 58(2):237-242

52. Di Luigi L et al (2008) The long-acting phosphodiesterase inhibitor tadalafil does not influence athletes' VO2max, aerobic, and anaerobic thresholds in normoxia. Int $\mathbf{J}$ Sports Med 29(2):110-115

53. Felici $\mathrm{F}$ et al (2016) Acute severe male hypo-testosteronemia affects central motor command in humans. J Electromyogr Kinesiol 28:184-192

54. Di Luigi L et al (2012) Andrological aspects of physical exercise and sport medicine. Endocrine 42(2):278-284 